\title{
Health services information and health services research from the British Isles to Europe to Asia, over 40 years
}

The British National Health Service began in 1948 and caused major changes in general practice as well as hospitals and in both health care and health information.

In the early days of this fournal articles on the organisation of general practice and its information requirements frequently appeared, and one of the earliest was this month's historical article on page 384 .

That article was published when the fournal was 10 years and the NHS was 8 years old (based on data collected in the 5 th year of age of the NHS). The information related to two general practices (one with five partners - an early example of group practice) in a housing estate in outer London built as part of the postwar housing programme. The six GPs were co-authors, the principal authors being John Brotherston and Sidney Chave, both at the time working at the London School of Hygiene and Tropical Medicine. Together with the GPs they endeavoured to use routine information from the practices to help understand not only the health of the community whom they were serving (for example, consultation rates and illness rates, in relation to age, gender, and socioeconomic status) but also the behaviour of the GPs (for example, hospital referrals, prescription rates).

They noted, for example, that $76 \%$ of the population consulted a GP at some time during the year, the average consultation rate being 4.1 per person per year. About $0.5 \%$ of the consultations took place between $8.00 \mathrm{pm}$ and 8.00 am - 70 in a year out of about 3000 patients in the sample. Only $5 \%$ of the practice population consulted the doctor without obtaining a prescription. Some $20 \%$ of all patients on the list were referred to hospital during the year. It is remarkable how the same topics of interest arise in discussions of primary care today.

The overall conclusion in the paper was: 'The value of record keeping by general practitioners is stressed, together with the need for a generally accepted method of expressing rates in studies of this kind'. John Brotherston went on to be Professor of Community Medicine in Edinburgh, Chief Medical Officer for Scotland, and President of the UK Faculty of Community Medicine (now Public Health Medicine). Sydney Chave remained at the London School of Hygiene and Tropical Medicine until his retirement, teaching and inspiring generations of public health students (including myself) about the past, present, and future of social medicine and community health. They helped set a pattern of cooperation between general practice and public health, which has been followed (albeit irregularly) over the years and has recently been urged upon readers of this Journal. ${ }^{1}$ The Journal has also recently encouraged readers to make good use of information about public health as well as clinical practice arising from general practice. ${ }^{2}{ }^{3}$

Other papers in this number refer to a variety of aspects of health services research ranging through France and Switzerland to Vietnam, and from heart disease to maternity services to accident and emergency services. The epidemiology papers range from cancer in Australia to ocular trauma in Scotland. A particular paper to mention with both epidemiology and health service research components and also ethnic dimensions relates to renal transplant recipients in a central part of England. The challenges of providing appropriate as well as effective health care remain for those aiming at evidence based practice in the health services and in public health.

STUART DONNAN Editor

1 Bhopal RAJ, Public health medicine and primary health care, convergent, diver Wivergent or parallel paths? F Epidemiol Community Health 1995;49:113-16. useful information? Evaluation of primary health care information project useful information? Evaluation of primary health care information project

3 Middelkoop BJC, Bohnen AM, Duisterhout, Hoes AW, Pleumeekers HJCM, Prins A. Rotterdam general practitioners report (ROHAPRO): a computerised network of general practices in Rotterdam, The Netherlands. $\mathcal{f}$ Epidemiol Community Health 1995;49:231-33. 